\title{
Optimization Process of Hummers with Large Diameter Graphite
}

\author{
Yeye $\mathrm{Xu}^{\mathrm{a}}$, Bo Xiao ${ }^{\mathrm{b}}$, Jiao $\mathrm{Yan}^{\mathrm{c}}$ \\ Department of Electronic Engineering, School of Electronic Information and Electrical \\ Engineering, Shanghai Jiao Tong University, Shanghai 200240, P.R. China

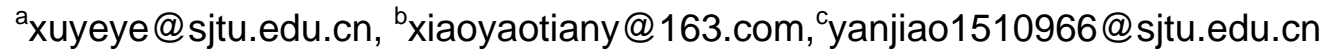

Keywords: Graphene oxide, Preparation, Diameter, Yield

Abstract. Graphene oxide (GO) is prepared from flake graphite. By changing graphite, reaction time and oxidant addition, the critical process that influenced the preparation is studied. Optimum reaction process of $1400 \mu \mathrm{m} / 710 \mu \mathrm{m}$ graphite is obtained with results of characterization and yield. With the introduction of standing, stirring resistance and stirring time of reaction process are decreased effectively, which could diminish energy consumption and requirements of experimental devices.

\section{Introduction}

Graphene, 2D graphite, is composed of sp2 hybridized carbon atoms, which are strictly packed into honeycomb lattices in monolayer [1-3]. It was first obtained by Geim in 2004 [4]. As a precursor of rGO, GO demonstrates its importance by affecting the structure, property and potential application of rGO [5]. There are some methods striving to produce graphene or its derivatives in large scale, for instance, micromechanical exfoliation, chemical vapor deposition, SiC epitaxial method and Hummers [6-9].

Hummer's advantages clearly reveal itself in aspects like simple process and realizable experimental conditions. However, the preparation process also has its drawbacks, such as quite long reaction time, high energy consumption by stirring and low yield of graphite with large diameter. These shortcomings limit the production of GO in industry. In Héctor A. Becerril's work, graphite of $4 \mu \mathrm{m}$ is employed as the reactant. Ingredients for $1 \mathrm{~g}$ graphite is: $82 \mathrm{ml} \mathrm{H}_{2} \mathrm{SO}_{4}, 0.75 \mathrm{~g} \mathrm{NaNO}_{3}, 4.5 \mathrm{~g}$ $\mathrm{KMnO}_{4}$ and $3 \mathrm{ml} \mathrm{H}_{2} \mathrm{O}_{2}$, along with reaction time more than $120 \mathrm{~h}[10]$. In Kai Zhang's work, fineness of original graphite is $49 \mu \mathrm{m}$. The blend of graphite and $\mathrm{NaNO}_{3}$ is mingled with $\mathrm{H}_{2} \mathrm{SO}_{4}$ first and then added with $\mathrm{KMnO}_{4}$, which is followed by vigorously stirring at room temperature overnight[11].

In this paper, the diameter of starting graphite was $1400 \mu \mathrm{m}$ and $710 \mu \mathrm{m}$ separately. Graphene oxide was synthesized on the basis of reaction process of $74 \mu \mathrm{m}$ graphite in our lab[12].Standing was brought into the process to realize energy saving and a meticulous study of different variables of the process has been done. Though other process of each flake can be achieved with high yield, by reducing stirring time and stirring resistance, the consumption of energy can be remarkably reduced in our process, which could be favorable for mass production in the future.

\section{Experiment}

Preparation of GO. $\mathrm{H}_{2} \mathrm{SO}_{4}(70 \mathrm{ml})$ was mixed with flake graphite ( $\left.2 \mathrm{~g}, 1400 / 710 \mu \mathrm{m}\right)$ and $\mathrm{NaNO}_{3}$ $(1 \mathrm{~g})$ under $0^{\circ} \mathrm{C}$ in $30 \mathrm{~min}$. After stirring for $30 \mathrm{~min}, \mathrm{KMnO}_{4}(9.8 \mathrm{~g})$ was added gradually in $1.5 \mathrm{~h}$. Then the solution was allowed to react for $2 \mathrm{~h}$ at $35^{\circ} \mathrm{C}$ and kept standing for $48 \mathrm{~h}$. After that deionized water was added into the blend. Later, aqueous solution of hydrogen peroxide was added into the blend as well. The product was processed by filtration, and washed with hydrochloric acid solution and deionized water.

Optimization of process of $1400 \mu \mathrm{m} / 710 \mu \mathrm{m}$. The amount of graphite was $2 \mathrm{~g}$ in all experiments, which were divided into two parts. In the first set of experiment, the amount of $\mathrm{NaNO}_{3}$ was fixed to 1 $\mathrm{g}$ and a definition was given to "a":

$$
\mathrm{a}=\text { concentrated } \mathrm{H}_{2} \mathrm{SO}_{4} 50 \mathrm{ml}+\mathrm{KMnO}_{4} 7 \mathrm{~g} \text {. }
$$


By changing $\mathrm{b}(\mathrm{b}=1 \mathrm{a}, 1.3 \mathrm{a}, 1.35 \mathrm{a}, 1.4 \mathrm{a}, 1.5 \mathrm{a}, 2 \mathrm{a}, 3 \mathrm{a}, 4 \mathrm{a})$, stirring time $(0.5 \mathrm{~h}, 1.5 \mathrm{~h}, 2 \mathrm{~h}, 6 \mathrm{~h}, 24 \mathrm{~h}$, $48 \mathrm{~h}$ ) and standing time $(24 \mathrm{~h}, 48 \mathrm{~h}, 84 \mathrm{~h})$, reaction conditions were determined preliminarily. To ascertain optimal amount of reactants, the correlation of yields and amount of $\mathrm{KMnO}_{4}$ and $\mathrm{NaNO}_{3}$ was discussed by changing the amount of $\mathrm{KMnO}_{4}(5 \mathrm{~g}, 5.5 \mathrm{~g}, 6 \mathrm{~g}, 6.5 \mathrm{~g}, 7 \mathrm{~g}, 7.5 \mathrm{~g}, 8 \mathrm{~g}, 8.5 \mathrm{~g}, 9 \mathrm{~g}, 10$ $\mathrm{g}, 11 \mathrm{~g})$ and that of $\mathrm{NaNO}_{3}(0.5 \mathrm{~g}, 1 \mathrm{~g}, 1.5 \mathrm{~g}, 2 \mathrm{~g})$.

\section{Characterization}

AFM images were acquired using a Multimode Nanoscope V scanning probe microscopy system (Bruker, USA). SEM figures were tested on an Ultra 55 field emission scanning electron microscope (Zeiss, Germany). UV-vis spectra was recorded on a Varian Cary $100 \mathrm{UV}$-vis spectrophotometer. The FT-IR analysis was performed with EQUINOX 55 FT-IR spectrometer (Bruker, Germany). Yield was calculated according to following equation:

$$
\mathrm{Y}_{\mathrm{GO}}=\mathrm{m}_{\mathrm{GO}} / \mathrm{m}_{\text {product }} \times 100 \%
$$

\section{Results and discussion}

The morphologies of GO were examined using electron microscopes. Graphene oxide prepared from $1400 \mu \mathrm{m}$ and $710 \mu \mathrm{m}$ was defined as GO1 and GO2 separately. Figure 1 shows AFM images of GO1 and GO2. It can be clearly observed that the height of GO sheets is less than $1.2 \mathrm{~nm}$, indicating that GO sheets are single layers [13].
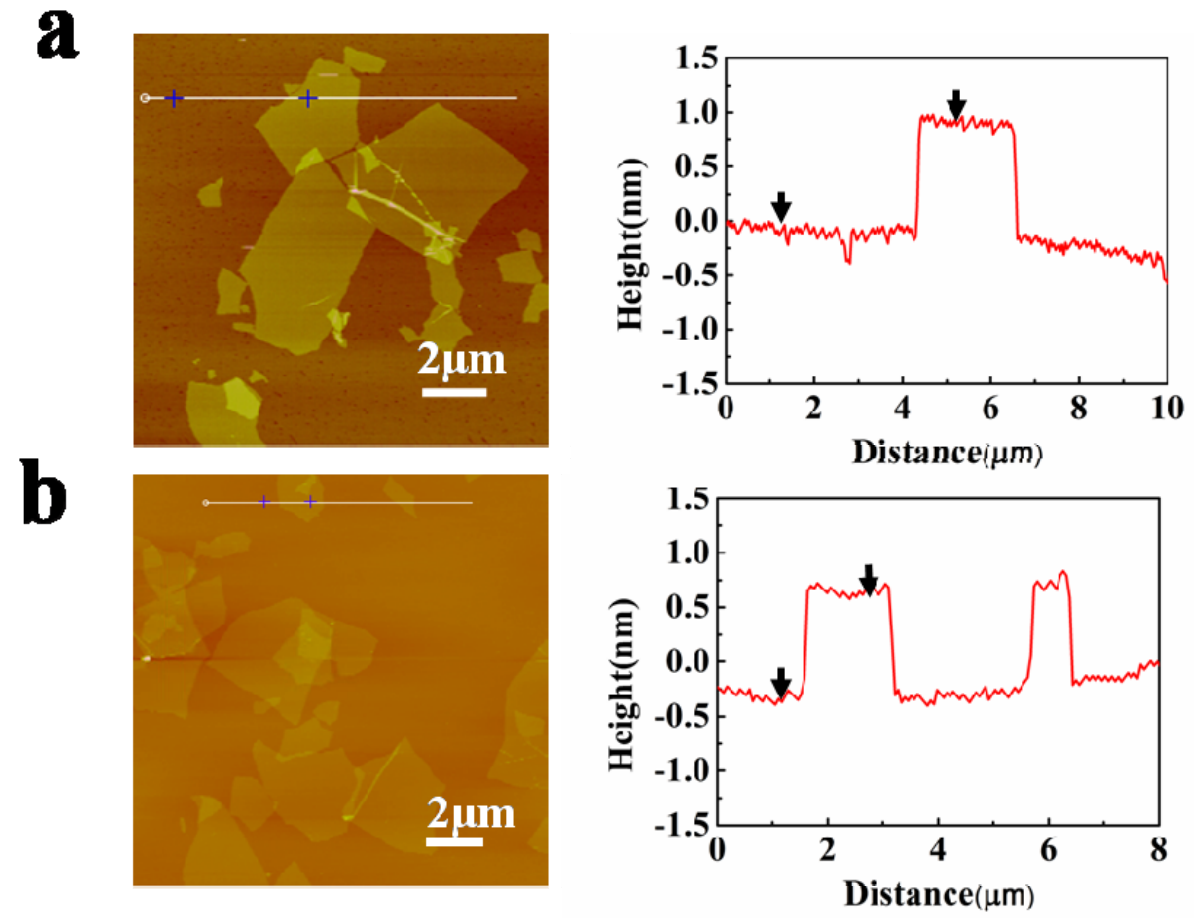

Fig. 1 (a) Tapping-mode AFM topography and height images of GO1 from $1400 \mu \mathrm{m}$ diameter graphite;

(b) Tapping-mode AFM topography and height images of GO2 from $710 \mu \mathrm{m}$ diameter graphite.

To probe deeply into size of GO sheets,images were taken by SEM and counted by Image J. As shown in Figure 2b, GO sheets demonstrated wide size distribution. GO1 covered an area ranging from $0.02 \mu \mathrm{m}$ to $120 \mu \mathrm{m}$. While size of GO2 varied from $0.02 \mu \mathrm{m}$ to $12 \mu \mathrm{m}$. Single layer plates in the range of 20 to $40 \mu \mathrm{m}$ accounted for $55 \%$ of total GO1. Similarily, GO2 had nearly $50 \%$ of sheets with 
size of $1-3 \mu \mathrm{m}$. Moreover, the average size of GO1 was much larger than that of GO2, indicating that the size of GO would, somehow, be influenced by starting graphite's size.
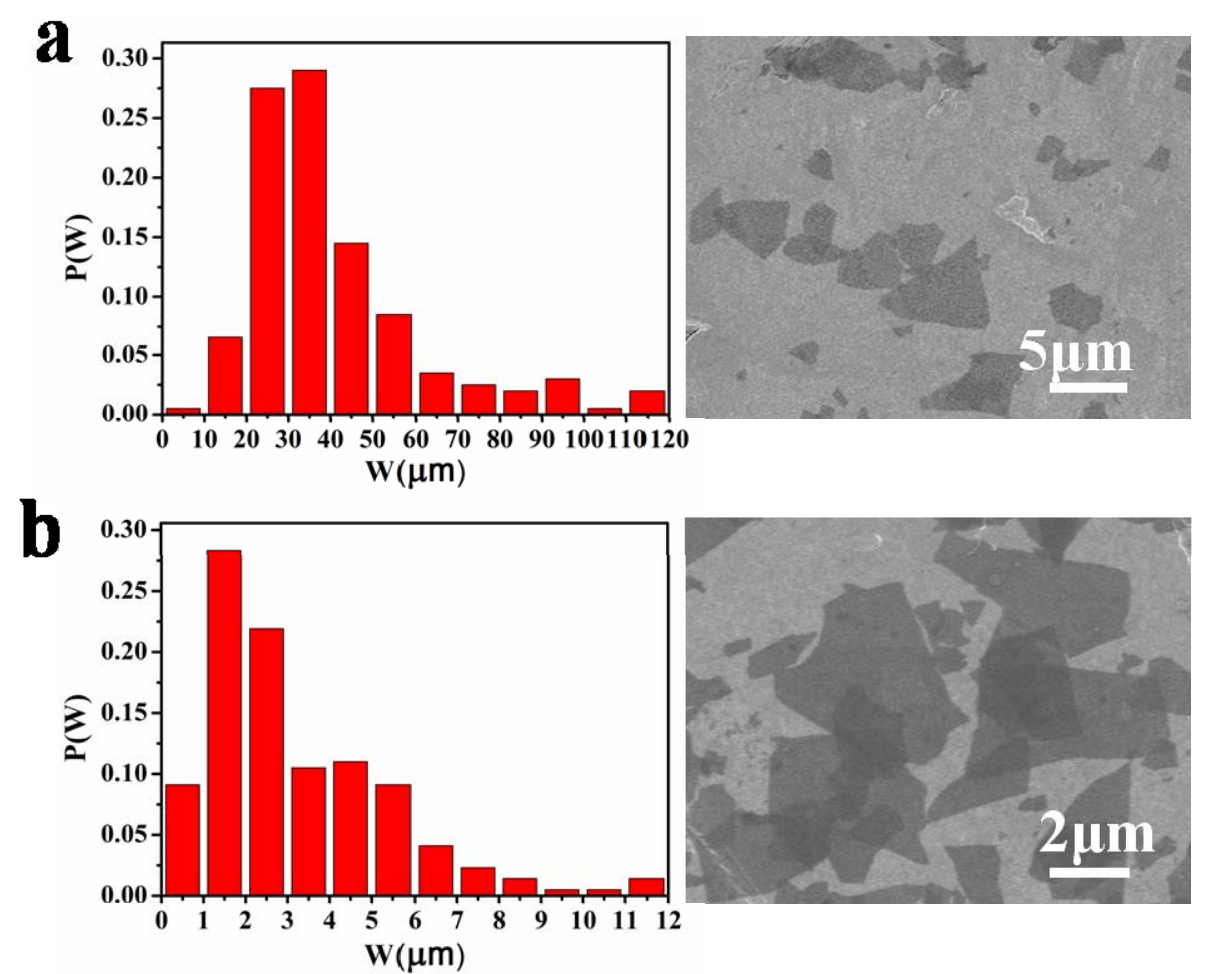

Fig. 2 (a) Size distribution and SEM images of GO1 from $1400 \mu \mathrm{m}$ diameter graphite;

(b) Size distribution and SEM images of GO2 from $710 \mu \mathrm{m}$ diameter graphite.

Moreover, chemical functional groups of products were characterized with FTIR and UV-vis. Figure 3 a shows the Fourier transform infrared spectrum of samples. Characteristic peaks of products can be seen below: $\mathrm{C}=\mathrm{O}$ stretching at $1737 \mathrm{~cm}^{-1}, \mathrm{C}=\mathrm{C}$ stretching at $1635 \mathrm{~cm}^{-1}, \mathrm{C}-\mathrm{O}$ stretching at 1230 $\mathrm{cm}^{-1}, \mathrm{C}-\mathrm{O}$ bending at $1407 \mathrm{~cm}^{-1}$ and $1070 \mathrm{~cm}^{-1}$ [14]. Figure $3 \mathrm{~b}$ revealed strong light adsorption in wide light spectrum from ultraviolet to visible light. The absorption peak appeared at $225 \mathrm{~nm}$, which was attributed to $\mathrm{p}-\mathrm{p}^{*}$ transition of aromatic $\mathrm{C}-\mathrm{C}$ single bonds[15]. FTIR spectrum and UV-vis proved that graphite was oxidized well.

$\mathbf{a}$

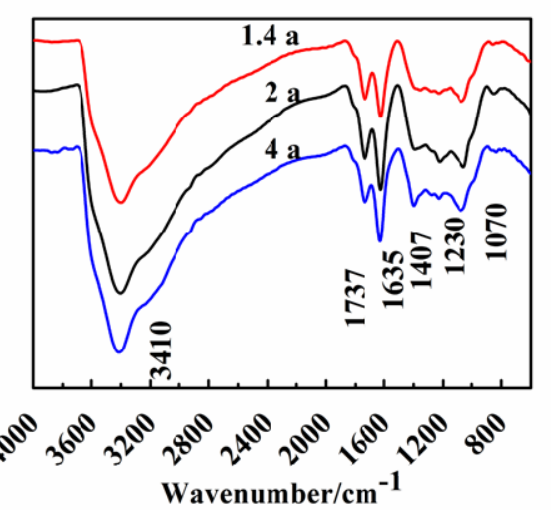

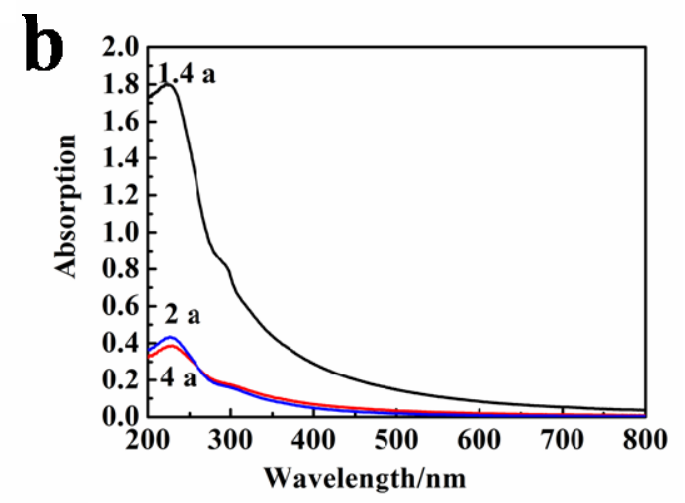

Fig. 3 (a) Fourier transform infared spectra (FT-IR) of GO sheets prepared with 1.4a, 2a, 4a;

(b) Ultraviolet visible spectra (UV-vis) of GO sheets prepared with 1.4a, 2a, 4a.

To identify primary reaction conditions, yields of GO1 were calculated on the basis of first set of experiments. The results revealed that the yield increased rapidly from $42.08 \%$ to $99.37 \%$, when the amount of reactants went up from 1a to $1.4 \mathrm{a}$. In the range of $1.4 \mathrm{a}-4 \mathrm{a}$, yields were more than $99 \%$ and tended to be stable. The amount of reactant was then kept at $1.4 \mathrm{a}$. It demonstrated that under the 
premise of high yield, both stirring and standing time can be reduced to $0.5 \mathrm{~h}, 2 \mathrm{~h}$ and $48 \mathrm{~h}$. Grounded on the findings of GO1, optimization experiments of GO2 were carried out. Yields of corresponding GO rose from $71 \%$ (1a) to $98 \%$ (1.3a). While $b$ was more than $1.3 \mathrm{a}$, yields maintained at more than $98 \%$

To further determine the optimal reaction conditions, relations between the yield and the amount of $\mathrm{KMnO}_{4}$ or $\mathrm{NaNO}_{3}$ are under in-depth discussion. For GO1, when increased the amount of $\mathrm{KMnO}_{4}$ from $9.8 \mathrm{~g}$ to $10 \mathrm{~g}, 11 \mathrm{~g}$, the yields were all over $99 \%$, with little change. On the other hand, the yield dropped sharply to $90 \%$ while the amount of $\mathrm{KMnO}_{4}$ was reduced to $9 \mathrm{~g}$. What's more, the yield fell below $80 \%$ when the amount was reduced to $6.5 \mathrm{~g}$. Similarily, we have done experiments on GO2, grounded on the previous amount of $\mathrm{KMnO}_{4}$, which was $9.1 \mathrm{~g}$. When increased the amount of $\mathrm{KMnO}_{4}$ to $10.5 \mathrm{~g}$, the yield of GO2 was over $98 \%$. Instead, with the amount reduced to $8.5 \mathrm{~g}$, the yield decreased to $90 \%$. The yield kept dropping sharply with continuous decrease of $\mathrm{KMnO}_{4}$. For instance, when the amount of $\mathrm{KMnO}_{4}$ was reduced to $4.9 \mathrm{~g}$, the yield dropped to $23.86 \%$. Based on these results, an optimal amount of $\mathrm{KMnO}_{4}$ for $\mathrm{GO} 1$ and $\mathrm{GO} 2$ should be $9.8 \mathrm{~g}$ and $9.1 \mathrm{~g}$ respectively. If the addition of $\mathrm{KMnO}_{4}$ was less than the required amount, it would fail to promote the fully formation of one-order sulfuric acid-graphite intercalation compounds at low temperature and further oxidation at high temperature, which led to incomplete intercalation at stages and yield decline.

In case of $\mathrm{NaNO}_{3}$, when reduced the amount of $\mathrm{NaNO}_{3}$ from $1 \mathrm{~g}$ to $0.5 \mathrm{~g}$, the yields of GO1 /GO2 dropped from $99.37 \%$ to $90.55 \%$ and from $98.15 \%$ to $92.90 \%$ separately. On contrary, while increased the amount to $1.5 \mathrm{~g}, 2 \mathrm{~g}$, the yields of GO1 and GO2 showed a slight decline, still retained at $95 \%$ or above. Hence, the optimal amount of $\mathrm{NaNO}_{3}$ of GO1 and $\mathrm{GO} 2$ should be $1 \mathrm{~g}$. Apparently, the oxidation function of $\mathrm{NaNO}_{3}$ was limited in the process. $\mathrm{HNO}_{3}$ was considered to be generated by reaction of $\mathrm{NaNO}_{3}$ and concentrated $\mathrm{H}_{2} \mathrm{SO}_{4}$, which accelerated oxidation of graphite. While the amount of $\mathrm{NaNO}_{3}$ decreased, oxidative ability of system declined slightly. Besides, absorptive capacity between edges of graphite and polar molecules was lower, resulting in some impact on intercalation process, thus a slight decrease in yield.

\section{Conclusion}

In this study, optimum process of $\mathrm{GO} 1$ and $\mathrm{GO} 2$ was successfully obtained through controlling variable method. Optimal process of GO1/GO2 was: $2 \mathrm{~g}$ graphite, $9.8 \mathrm{~g} / 9.1 \mathrm{~g} \mathrm{KMnO}_{4}, 1 \mathrm{~g} \mathrm{NaNO}_{3}, \mathrm{t}_{1}$ $0.5 \mathrm{~h}, \mathrm{t}_{2} 2 \mathrm{~h} / 48 \mathrm{~h}$. Results of AFM and SEM suggested that GO sheets were single layers and size distribution of them was influenced by graphite's diameter. Analysis of FT-IR and UV-vis proved that these products were typical GO sheets. Besides, reaction time was reduced greatly by the introduction of standing. We envisage that the optimized preparation process of GO should accelerate its industrial production.

\section{References}

[1] Raccichini R, Varzi A, Passerini S, et al. The role of graphene for electrochemical energy storage[J]. Nature materials, 2015, 14(3): 271-279.

[2] Novoselov K S, Geim A K, Morozov S V, et al. Electric field effect in atomically thin carbon films[J]. science, 2004, 306(5696): 666-669.

[3] Lin Y C, Cao Y, Jang J H, et al. The synthesis and characterization of graphene oxides based on a modified approach[J]. Journal of Thermal Analysis and Calorimetry, 2014, 116(3): 1249-1255.

[4] Geim A K, Novoselov K S. The rise of graphene[J]. Nature materials, 2007, 6(3): 183-191.

[5] Zhu Y, Murali S, Cai W, et al. Graphene and graphene oxide: synthesis, properties, and applications[J]. Advanced materials, 2010, 22(35): 3906-3924. 
[6] Berger C, Song Z, Li X, et al. Electronic confinement and coherence in patterned epitaxial graphene[J]. Science, 2006, 312(5777): 1191-1196.

[7] Berger C, Song Z, Li T, et al. Ultrathin epitaxial graphite: 2D electron gas properties and a route toward graphene-based nanoelectronics[J]. The Journal of Physical Chemistry B, 2004, 108(52): 19912-19916.

[8] Hu Z L, Aizawa M, Wang Z M, et al. Synthesis and Characteristics of Graphene Oxide-Derived Carbon Nanosheet- Pd Nanosized Particle Composites[J]. Langmuir, 2010, 26(9): 6681-6688.

[9] Hummers, W.S. and R.E. Offeman, Preparation of Graphitic Oxide. Journal of the American Chemical Society, 1958. 80(6): p. 1339-1339.

[10]Becerril H A, Mao J, Liu Z, et al. Evaluation of solution-processed reduced graphene oxide films as transparent conductors[J]. ACS nano, 2008, 2(3): 463-470.

[11]Zhang K, Zhang L L, Zhao X S, et al. Graphene/polyaniline nanofiber composites as supercapacitor electrodes[J]. Chemistry of Materials, 2010, 22(4): 1392-1401.

[12]Zhang J, Yang H, Shen G, et al. Reduction of graphene oxide via L-ascorbic acid[J]. Chemical Communications, 2010, 46(7): 1112-1114.

[13]Bai H, Li C, Shi G. Functional composite materials based on chemically converted graphene[J]. Advanced Materials, 2011, 23(9): 1089-1115.

[14]Li D, Mueller M B, Gilje S, et al. Processable aqueous dispersions of graphene nanosheets[J]. Nature nanotechnology, 2008, 3(2): 101-105.

[15]Marcano D C, Kosynkin D V, Berlin J M, et al. Improved synthesis of graphene oxide[J]. ACS nano, 2010, 4(8): 4806-4814. 